\title{
versants
}

REVISTA SUIZA DE LITERATURAS ROMÁNICAS

Revista publicada bajo el auspicio del Collegium Romanicum

(Asociación de los Romanistas Suizos)

con el apoyo de la Academia Suiza

de Ciencias Humanas y Sociales

NÚMERO 63:3 (FASCÍCULO ESPAÑOL)

2016

TEORÍA/S

Número editado

por Bénédicte VAUTHIER

SLATKINE

GINEBRA

Difusión en Francia:

HONORÉ CHAMPION ÉDITEUR,

París 
Soutenu par l'Académie suisse des sciences humaines et sociales www.assh.ch

(C) 2016. Éditions Slatkine, Genève. www.slatkine.com

Reproduction et traduction, même partielles, interdites.

Tous droits réservés pour tous les pays.

ISBN 978-2-05-102791-5 ISBN 978-2-05-102792-2

ISSN 0256-9645 


\section{Para una historia del relato de viaje hispánico (siglos XIX-XXI): noticia de una investigación en marcha}

\section{Introducción}

Durante el último cuarto de siglo, la literatura de viaje ha dejado de ser una actividad relativamente secundaria en el ámbito hispano y hoy ocupa secciones específicas en librerías y en medios de comunicación, recibe la atención de congresos científicos, es objeto de premios literarios y permite que cierta cantidad de autores se dedique a ella de forma casi exclusiva. La posibilidad de desplazarse por todo el planeta, la extensión de la sociedad del bienestar, el interés creciente por determinados espacios y las nuevas posibilidades editoriales son algunas de las razones que han favorecido un proceso ya impulsado en la segunda mitad del siglo XIX gracias al tren como nuevo sistema de desplazamiento y al crecimiento exponencial de la prensa, que acoge numerosas crónicas viajeras, parte de las cuales se convertirá luego en libro.

No obstante, si bien la sociedad contemporánea ha estimulado esa expresión literaria en una medida hasta entonces inédita, dicha actividad arranca en los orígenes de nuestra literatura y la ha acompañado e incluso enriquecido generosamente a lo largo de su historia. Desde la epopeya de Gilgamesh hasta las creaciones del siglo actual, el viaje ha sido un tema constante de las letras occidentales. Recuérdense creaciones como la Odisea, la Eneida, la relación de Marco Polo, la Embajada a Tamorlán, las crónicas de la conquista americana, el Quijote, las memorias de expediciones a lo largo y ancho del globo, los Viajes de Ponz en el XVIII español, los relatos viáticos de Mesonero, la narrativa de Verne, los textos de Bouvier, Chatwin y Kerouac en el siglo pasado, etc. ${ }^{1}$.

\footnotetext{
${ }^{1}$ Hemos desarrollado este punto en Julio Peñate Rivero, «La poética del libro de viaje entre la Edad Media y el siglo XXI», Letras. Revista de la Pontificia Universidad Católica Argentina, 71, 2015 (enerojunio), pp. 41-62.
} 
Pero ya aquí conviene hacer un primer deslinde, pues nuestro campo de estudio no se refiere al viaje en la literatura de ficción: el tópico sería tan general que perdería funcionalidad e interés para el análisis (la historia literaria "está llena» de personajes que se desplazan: el objeto de estudio se volvería inabarcable). Así pues, por 'materia viática' entenderemos aquí un viaje factual, efectivamente realizado por su autor y narrado luego por él.

Si bien el viaje es condición para la existencia del relato (si no, se trataría de la narración ficcional de un desplazamiento imaginario), el texto no se identifica con la experiencia viática: el libro no es el viaje, aunque debe corresponder a él, y es precisamente el libro nuestro objeto primordial de estudio. Componer un relato implica una multiplicidad de operaciones, cada una más delicada que las demás. Aunque volveremos sobre este punto más tarde, citemos aquí cuatro categorías que nos parecen significativas y que suelen intervenir de forma sucesiva: en primer lugar, una selección dentro de la masa de materiales que el viaje ha dado de sí a partir de su interés propio, de su excepcionalidad o de su valor representativo, de su tono dramático o entretenido, de su potencial impacto ante el lector, etc.; en segundo lugar, la organización de esos materiales dentro del texto, su orden de aparición, su presentación seguida o fragmentada, su narración por extenso, resumida o eligiendo sólo una parte de la peripecia; en tercer lugar, su articulación con secuencias descriptivas o informativas respecto a la historia del lugar y de sus habitantes, de sus tradiciones, de su estructura social, de su producción cultural, etc.; finalmente, la puesta en discurso de todo lo anterior como diario, carta, informe, documento en bruto o elaborado, con sus recursos estilísticos... Se culmina así una tarea compositiva delicada y exigente, que conlleva una alta dosis de organización, de imaginación, de competencia expresiva y, en definitiva, de creatividad literaria.

A todo lo anterior se añade la gran riqueza de conexiones entre el relato de viaje y otras series narrativas como la autobiografia, la autoficción, la crónica por entregas, el documento etnográfico, el estudio resultante de una expedición científica, etc. Se ha dicho que la fuerza de la novela consiste en su capacidad de incluir los demás géneros; en el relato de viaje caben tanto la novela como modalidades discursivas a priori no literarias, lo cual, si no constituye su fuerza, sí lo reviste de una 
especial complejidad. Por ejemplo, de forma explícita o implícita, el relato viático contiene una dimensión antropológica de acuerdo con la experiencia realizada: el viaje digno de ese nombre, el que interesa de veras a esta narrativa, no es el de tipo balneario o paisajístico (aunque pueda incluir esos y otros elementos) sino el que supone un encuentro con la alteridad, con la diferencia, con otros modos de hacer la historia y de entender la vida. A la hora de examinar dichos textos, tal vez no basten las habituales competencias en análisis del discurso sino que sean necesarias otras en los asuntos abordados por el relato así como una perspectiva de análisis transdisciplinar.

\section{Sobre el estado de la cuestión}

Una investigación se caracteriza tanto por los resultados que va logrando como por el procedimiento que lleva a ellos. La constitución de una metodología y la revisión periódica de su adecuación al objeto de estudio son tareas imprescindibles para evaluar la conveniencia de seguir por la vía iniciada o de realizar un cambio de rumbo. Por esta razón exponemos en las páginas que siguen la forma como hemos procedido, empezando por una breve descripción del panorama que motivó nuestra investigación y que orientó la dirección de nuestro camino y el modo de recorrerlo. En grandes líneas y según la información disponible, la situación previa a nuestra investigación, en lo relativo a las letras hispanas, podría resumirse en los siete puntos siguientes:

1. Claro predominio de la recopilación de ensayos breves como resultado de encuentros académicos y de monografias en revistas literarias. Se trataba, por lo general, de un conjunto de artículos consagrados a textos pertenecientes a épocas diferentes, a veces desde el medievo hasta la actualidad. Podían abordar el ámbito americano, el español, reunir ambos o insertar los artículos en publicaciones referidas conjuntamente a países hispanos y de otras lenguas.

2. Concentración preferente en torno a la Edad Media, con estudios de notable interés histórico y filológico, panorámicas generales densas y documentadas, ediciones de textos cuidadas y ricas en información, etc. A ello se añade una reflexión teórica muy notable, practicada por 
investigadores de orientaciones y competencias diversas. Buena parte de tales contribuciones sigue siendo válida actualmente: nosotros mismos las hemos utilizado en nuestra investigación, muchas veces a título comparativo, con resultados satisfactorios, ya sea para constatar homologías o para fijar diferencias.

3. Cantidad, temáticas y desarrollo relativamente escaso de estudios sobre los dos últimos siglos, en especial sobre el xx, durante el cual la literatura de viaje ha crecido de forma exponencial (a pesar de que «ya no hay nada por descubrir»).Y dentro de estos estudios, muchos y muy meritorios se quedan en una etapa calificable de preliminar. La situación podría considerarse como inversa a la de la época medieval.

4. Indefinición de la perspectiva crítica. Con frecuencia, en muchos de los textos objeto de estudio o de comentario crítico falta un análisis realizado desde el ángulo específico de la literatura de viaje, hasta el punto de situar en el mismo plano relatos de viaje y relatos con viaje (en los cuales el componente viático viene a ser un elemento de la diégesis entre otros) o de centrarse en el viajero más que en el propio relato.

5. Dificultad para localizar una gran parte de los textos publicados. Los motivos suelen añadirse unos a otros: escritos a veces por autores ignorados, sin capacidad para hacerlos conocidos, editados en tiradas muy limitadas, ausentes de bibliotecas y de centros de investigación, conservados gracias a la curiosidad de libreros y anticuarios, cuando no están simplemente desaparecidos, etc.

6. Ruptura de una posible continuidad: aparecidos en la prensa, numerosos relatos de excelente nivel no llegan a editarse en libro. Las razones pueden ser múltiples (a veces el propio autor se muestra reacio a la publicación). El hecho es que muchas crónicas periodísticas de los siglos XIX y XX merecerían esa segunda oportunidad. Véanse, por ejemplo, las Aguafuertes de asunto español editadas por Sylvia Saítta años después de la desaparición de Roberto Arlt.

7. Déficit de reconocimiento literario. Un libro de viaje ha venido siendo considerado como un texto menor dentro de la producción de un escritor reconocido y, si su obra se limita a la literatura viática, fácilmente recibirá él también la calificación de 'escritor menor': en las letras hispánicas un autor difícilmente ha obtenido el respeto de la crítica cultivando únicamente este tipo de escritura. 
En resumen, la investigación ha puesto de relieve cierta cantidad de rasgos relativos a la descripción, al tratamiento del espacio y del tiempo, a la evolución del protagonista, a nociones como periplo, descripción o intertextualidad aplicadas al relato viático, etc. En cambio, al profundizar en la naturaleza del objeto, el investigador constata su variedad formal, las fronteras e interferencias entre lo ficcional y lo factual, el comportamiento de ciertos componentes textuales, la diversidad de géneros literarios que intervienen, las varias fases de elaboración textual, las conexiones con otras disciplinas... y dada la dificultad de controlar tantas variables, corre el riesgo de definir el objeto de estudio como conceptual y materialmente inabarcable.

La situación descrita concierne sobre todo al dominio hispánico, por lo que también hemos examinado numerosos estudios pertenecientes a otras literaturas, de los cuales hemos extraído datos y reflexiones de interés para nuestra investigación. No obstante, hemos observado que las características de los relatos, el marco cultural en el que se han producido, su situación en la historia general y literaria, etc., no siempre son aclimatables al contexto hispánico y, cuando lo son, debe hacerse con precaución y prudencia.

En nuestro caso concreto, la amplitud de la tarea hizo que esta se prolongara en el tiempo (lo cual ha podido tener la ventaja de madurar ciertos análisis y conceptos): la primera fase arrancó a inicios de 2004, ya que uno de los útiles principales de trabajo, el esquema de análisis aplicable a los diferentes textos, apareció ese año dentro de las actas de un coloquio internacional celebrado en la Universidad de Friburgo ${ }^{2}$. La colaboración de participantes como Fernando Aínsa, José Carlos Mainer y Lorenzo Silva, entre otros, nos ayudó a trazar panorámicas y a desbrozar el camino. Vino luego el estudio detallado de una obra en particular, la de un representante incuestionable de la literatura de viaje, Javier Reverte, cuyos textos fueron analizados en un nuevo coloquio (enero de 2005), que dio igualmente lugar a una publicación con la participación del autor ${ }^{3}$.

\footnotetext{
2 Julio Peñate Rivero (ed.), Relato de viaje y literaturas hispánicas, Madrid,Visor, 2004. Se trata de una primera versión, adaptada posteriormente según lo exigiera la investigación.

${ }^{3}$ Julio Peñate Rivero (ed.), Leer el viaje. Estudios sobre la obra de Javier Reverte, Madrid,Visor, 2005. El ensayo de Reverte "¿Por qué viajo?» (pp. 29-43) es de gran interés para comprender la obra de este autor.
} 
Convenía acotar temporalmente un campo de investigación que se revelaba cada vez más rico y extenso: se imponía la limitación al siglo XX (con algunos precedentes y continuaciones) para volverlo más comprensible y abarcable. Así lo hicimos coordinando una sección en el XVI Congreso de la Asociación Alemana de Hispanistas (Leipzig, marzo de 2007), con la contribución de Luis Alburquerque, Sofia Carrizo Rueda, Geneviève Champeau y otros investigadores. Los trabajos de la sección y la publicación posterior ${ }^{4}$ confirmaron la pertinencia de la limitación temporal citada y la necesidad de concentrarse en la narrativa factual dejando de lado la reconocida como ficcional: existen, sin duda, múltiples elementos comunes, pero la investigación gana en operatividad y en rigor focalizándose sobre uno de los dos discursos.

La segunda fase de la investigación se abre en ese mismo año 2007 , con un período de búsqueda, en una decena de bibliotecas europeas y americanas, de nuevos textos susceptibles de ser añadidos a nuestro corpus a partir de su consonancia con nuestro esquema de análisis inicial y de las siguientes pesquisas. La cadena de descubrimientos hace necesaria la incorporación de un equipo de colaboradores encargados de retener o desechar los textos sometidos a lectura y de elaborar informes sobre los retenidos para análisis. Con esta finalidad recibimos una ayuda del Fondo Nacional Suizo de Investigaciones Científicas que nos permitió contratar tres colaboradores por un total de treinta meses.

Una vez elaborados, discutidos y corregidos los informes, una parte de ellos es retenida para su corrección, ampliación, reducción o modificación, lo que nos permite iniciar la tercera fase de la investigación. Dado que conocer implica generalizar los resultados obtenidos, proyectamos sobre un grupo más amplio de relatos las observaciones extraídas de las monografias realizadas para cada una de las etapas en que hemos dividido el siglo XX. Dicho grupo se compone del conjunto de textos retenidos para nuestra investigación, motivo por el cual el período de confrontación ha requerido tiempo y dedicación, pero es indispensable para obtener un balance global válido en cada etapa.

\footnotetext{
${ }^{4}$ Julio Peñate Rivero \& Francisco Uzcanga Meinecke (eds.), El viaje en la literatura hispánica: de Juan Valera a Sergio Pitol, Madrid,Verbum, 2008.
} 
Sin entrar en detalles, pues aparecen en la publicación resultado de nuestro estudio, la investigación ha permitido distinguir tres grandes etapas en el relato de viaje hispano del siglo XX y primeros años del actual: 1898-1940, 1941-1980 y 1981-2006, con una serie de características distribuidas en cuatro planos: el de la diégesis, el de la estructura, el de la expresión y el de la significación. Cada una de las etapas se justifica por poseer rasgos propios, mostrando tanto variaciones y rupturas como continuidades respecto a las demás 5 .

\section{Para una metodología de análisis}

El objeto de estudio no viene suscitado tal cual por la realidad sino que es el investigador quien lo construye a partir de la búsqueda y selección de materiales y de un dispositivo teórico capaz de poner de relieve las características, variantes y evolución del corpus objeto de análisis, es decir, a partir de un discurso atento a los hechos y capaz de extraer de ellos los rasgos pertinentes que den sentido a la investigación. Ese dispositivo ha de ser funcional: realmente aplicable a su objeto de estudio; además, productivo: válido para extraer conclusiones significativas; y también flexible: capaz de adaptarse a los nuevos textos que la literatura viática vaya generando. Por consiguiente, lejos de quedar fijado una vez por todas, dicho dispositivo está llamado a evolucionar, afinarse, enriquecerse, para seguir siendo operativo e incluso serlo cada vez más. De lo contrario, se corre el riesgo de forzar un texto "díscolo», que no encaje en el esquema, para hacerle entrar en él y quizás perder buena parte de lo que ese texto contiene de propio, de original, de renovador, etc.

Para ello es necesario elaborar una base de análisis adecuada al objeto de la investigación. En nuestro caso, ha tomado la forma de un esquema en cuatro apartados aplicable al corpus de textos previamente elegidos así como a aquellos que se incorporen posteriormente. Así pues, a través de la dinámica 'construcción-actualización' ha tomado el formato que aparece en estas páginas.

\footnotetext{
${ }^{5}$ Julio Peñate Rivero (ed.), Introducción al relato de viaje hispánico del siglo xx: textos, etapas, metodología. Vol. I: 1898-1980. Vol. II: 1981-2006, Madrid,Visor, 2012.
} 


\section{Esquema de análisis}

I. PLANO DE LA DIÉGESIS

1. Existencia de un desplazamiento físico por parte del viajero con:

- Paso de lo conocido a lo desconocido (espacio y situaciones)

- Diégesis basada en el desplazamiento y sus consecuencias

- Tematización explícita o sugerida del regreso o de su ausencia

2. Proyecto (destino, finalidad) y su problemática con:

- Carácter definido/indefinido, variable/constante, único/múltiple

- Dificultad para realizarlo (obstáculos y ayudas eventuales)

3. Actores (viajeros, guías, intermediarios, personajes locales): variantes, relaciones, funciones

4. Medios de desplazamiento y su implicación (por ej.: en las relaciones internas/externas de los actores)

5. Fuentes de información: identidad, origen, calidad, función

6. Impacto del viaje en el viajero: reflexión, interrogantes, modificación interior

7. Presencia del Otro (personal, colectivo, abstracto): contenido, protagonismo, visión sobre él y de él

II. PLANO DE LA ESTRUCTURA

1. El viaje como elemento movilizador del discurso narrativo: condición del relato, factor estructurante, generador de la intriga, distribución en el texto en relación con otros componentes (por ej.: las informaciones de contenido histórico, el ensayo sociopolítico, etc.)

2. Narrador: modalidades de su presencia, funciones, relación entre el narrador como actor en la peripecia y como autor de la narración

3. Historia: una o varias, distribución a lo largo del texto, diacronía (lineal o no), puntos de especial énfasis, relación con los otros elementos del texto

4. Descripción y digresión: espacios (ciudad/campo, interior/exterior), personajes, sensaciones, situaciones, relaciones mutuas y respecto a la historia o a otros componentes textuales

5. Interlocución: intercambios verbales entre los actores del viaje (en discurso directo o en otras modalidades), situación dialogal o jerárquica, consecuencias eventuales (para los actores y para la estructura del relato)

6. Ritmo discursivo: condicionado por los puntos anteriores, conviene tenerlo en cuenta, por ejemplo, para precisar el peso relativo de dichos puntos

7. Modalidades textuales de género diverso (diario, carta, ensayo, autobiografia, cuento, escena teatral, etc.): presencia y función

8. Materiales importados: historiográficos, filosóficos, políticos u otros, citas de otros escritores viáticos o no, retoma confesada o no de sus textos, mapas, repertorios bibliográficos, etc., formas e interés de su presencia 
III. PLANO DE LA EXPRESIÓN

1. Tipo de lenguaje: niveles de lengua, neologismos, extranjerismos, términos científicos, dialectalismos, vulgarismos, plurilingüismo, etc., y su carácter (signo de competencia, de interés por el Otro, etc.)

2. Recursos retóricos: comparación, generalización, enumeración, hipérbole, sinécdoque, prolepsis, analepsis y otros, su frecuencia y su posible función

3. Estilo o tonalidad expresiva (sobriedad, énfasis, corrección, espontaneidad fingida o no): en cuanto característica general del discurso o en momentos muy concretos del relato

IV. PLANO DE LA SIGNIFICACIÓN

1. Visión del mundo: explícita/implícita, cambiante o estable (lo que el texto dice o sugiere sobre el mundo y sobre el autor del libro)

2. Destinatario: según la intención del autor y la de la obra (por sus características internas)

3. Estatuto del texto: el recibido hasta ahora y el susceptible de merecer dentro de la Historia de la literatura de viaje y de la Historia de la literatura en general

4. Interés en relación con otros géneros y disciplinas, particularmente en ciencias humanas

\section{Tres conceptos fundamentales}

Toda construcción teórica necesita un aparato conceptual que viene a ser como el léxico con el que opera a la hora de enfrentarse a su objeto de estudio. Para que no se imponga a este haciéndole decir lo que ella quiere y convierta el análisis en una mera autoafirmación, tal dispositivo (al igual que el esquema ya comentado) ha de evolucionar y de reformarse para seguir en consonancia con dicho objeto. El procedimiento reviste básicamente dos formas: la creación de un nuevo concepto (usando un vocablo inédito o preexistente) y, más frecuentemente, la adaptación de uno ya usado en otro género o disciplina.

Presentamos aquí tres vocablos del segundo grupo. El primero nos muestra que el proceso de composición del texto viático conlleva una ficcionalidad tal vez inesperada en unos relatos basados en la factualidad. El segundo manifiesta un funcionamiento bastante distinto del que se le atribuye en la literatura llamada ficcional. El tercero interesa por la diferencia de su estatuto: si en otras series narrativas es mal visto y prescindible, aquí puede considerarse como un componente discursivo del mayor interés. 


\section{Ficcionalización}

Un relato de viaje es una construcción textual con sus normas y convenciones en torno a la descripción, la digresión, la progresividad, la figura del narrador, el tratamiento del espacio y del tiempo, el uso de determinados recursos retóricos, etc. Javier Reverte sintetiza un modo de proceder muy común entre los escritores viáticos: tras subrayar la realidad de sus personajes y escenarios, añade: «No obstante, algunas situaciones han sido retocadas con toda deliberación por el autor, de forma tal que, trastocando un poco la realidad, ganase la coherencia del relato. A veces hay que ajustar la realidad a la imaginación para aproximarse mejor a la verdad ${ }^{6}$. Citemos algunos procedimientos compositivos que apoyan la naturaleza del relato viajero como creación textual de carácter estético a partir de una experiencia factual:

- Supresión, invención o modificación de actores del viaje factual. Por ejemplo, Del Miño al Bidasoa de Camilo José Cela termina con un «Censo de personajes» en el que se distingue entre personajes reales y ficcionales. Estos últimos son unos setenta y entre ellos figura el equilibrista y vagabundo Dupont, uno de los actores más asiduos del relato (el mismo procedimiento interviene en Primer viaje andaluz, también de Cela).

- Inserción de un protagonista narrador y de un narratario al que el primero se dirige de manera explícita («lector», «lectora», «nosotros») como forma de implicarle en la historia. Nuevo viaje de España de Víctor de la Serna, obra en la que el narrador se refiere reiteradamente a un narratario a modo de compañero de viaje, abunda en ejemplos: «encontramos por el camino», «estamos en», «subamos», «retrocedemos», "cuando entramos», etc.

- Diálogo de composición: coloquios en estilo directo aun sin haber sido grabados o transcritos, pero que se nos presentan como si lo hubieran sido. Con mayor motivo, veremos ficcionalidad en los diálogos claramente creados para el texto y en los desdoblamientos del narrador protagonista consigo mismo, por ejemplo, en el extenso «autodiálogo» que cierra Rusia es otra cosa de Manuel del Arco.

\footnotetext{
${ }^{6}$ Javier Reverte, El sueño de África. En busca de los mitos blancos del continente negro, Madrid, Alianza, 2003, p. 9.
} 
- Distinción formal (cuando esta se produce) entre narrador y protagonista: recuérdese el recurso a sujetos nominales como «el viajero» (tan del gusto de Cela y del Llamazares de Trás-os-Montes), «el caminante» (por ejemplo, en Caminos de La Mancha de José Antonio Vizcaíno), «el peregrino» en el Moix de Terenci del Nilo, «el cronista», «el forastero», etc., y el verbo en tercera persona de singular.

- Incorporación de elementos de origen previático o postviático como si fueran intraviáticos: datos de un lugar que en realidad se han conocido documentándose posteriormente (a veces con inclusión de informaciones sobre sitios que no se han visitado), lecturas, recuerdos y reflexiones surgidos al componer el texto pero presentados como pertenecientes al viaje, etc. Así sucede, por ejemplo, en Del Rif al Yebala de Lorenzo Silva.

- Supresión, invención o alteración de acciones, de peripecias, de etapas, etc., o cambio de orden respecto al viaje real. Recordemos el dramatismo con el que Corpus Barga refuerza la intriga de Un viaje en el 19 y el comienzo de Vagabundo en África: Reverte decide abrir su relato con un hecho muy posterior al inicio del viaje y que se desarrollará unas cuatrocientas páginas después.

- Concentración de varios viajes (o de parte de ellos) en un solo texto, como si pertenecieran a una única expedición. El autor puede mezclar diferentes periplos de forma no del todo consciente, pero también puede ocurrir que la simbiosis sea voluntaria y difícilmente perceptible para el lector. Por si acaso, Jordi Esteva nos advierte de entrada: «En cuanto a mis viajes por las islas de la costa suajili con Cheij Nabhani, los he fundido en uno en aras de la fluidez del relato» ${ }^{7}$.

\section{Descripción}

Si en la novela la descripción ha sido considerada como un mero instrumento al servicio de la narración (ancilla narrationis), en el texto viático es un componente casi indispensable, dotado de importantes modalidades y funciones: la topografia y la prosopografia interesan

\footnotetext{
7 Jordi Esteva, Los árabes del mar. Tras la estela de Simbad: de los puertos de Arabia a la isla de Zanzíbar, Barcelona, Península, 2012, p. 5.
} 
especialmente pero también es relevante, por ejemplo, la etopeya del propio viajero ante lo que descubre en el camino y puede ocupar gran parte del texto viático. Destacaremos, como muestra, las siguientes:

- Descripción por ausencia: en el pueblo de Pampa Unión, cerca de Antofagasta, no hay orden en el trazado de las calles, no hay plaza central, no hay iglesia, no hay más que ruinas, según lo describe Ariel Dorfman en Memorias del desierto para referirse a lo que cabía esperar de un lugar antes dotado de sorprendentes realizaciones urbanísticas.

- Descripción por reticencia: postular un objeto o una experiencia como indescriptible (por su grandeza, novedad, riqueza, imposibilidad de compararlo con otro, etc.) puede ser un recurso eficaz y a veces también el único apuntado como utilizable, para evocar dicho objeto o la sensación que ha provocado en el viajero.

- Descripción en movimiento: es muy usada en el relato viático para referirse a lo percibido desde un medio de transporte o incluso caminando. Se compone de pinceladas rápidas o de simples enumeraciones, acordes con la rapidez del desplazamiento y la sucesión de objetos o personajes ante los que pasa el viajero. También se produce cuando es el observado el que se desplaza y se puede acrecentar si se suman ambos movimientos.

- Autentificación: mediante las características y los detalles que aporta, «garantiza» la realidad del objeto y su presencia en el espacio y en el tiempo del viaje. No obstante, esta garantía es relativa: cabe la posibilidad de que la realidad del objeto no corresponda a su descripción, que pertenezca a otro viaje, que sea básicamente inventado, etc.

- Jerarquización: la descripción supone una selección de lo que merece ser notado y de lo que lo merece con mayor detalle. Se establece así una jerarquía entre la multiplicidad de objetos y de experiencias a los que se ha tenido acceso durante el recorrido. Junto con la narración y la digresión, la descripción es un elemento discursivo esencial para marcar diferencias entre relato y viaje. En este opera el principio de realidad factual: todo ocurrió. En cambio, el relato inevitablemente filtra y reorganiza al traducirla en texto.

Nótese también la existencia de otros elementos, sobre todo de orden visual, que pueden acompañar o reemplazar a la descripción (dibujos, planos, fotos), lo cual permite ganar en precisión, economizar espacio, dar mayor intensidad emocional o testimonial, etc., además de 
ofrecer una variedad de procedimientos susceptibles de reforzar el aliciente del relato.

\section{Digresión}

Junto con la narración y la descripción, la digresión constituye un ingrediente primordial en la narrativa de viaje, llegando a dominar sobre los otros dos en obras como La alegría de andar de Eduardo Zamacois y Volcanes dormidos de Regàs y Molina Temboury o al menos tener una gran presencia textual (léase la trilogía africana de Reverte). El objeto viático interesa por lo que es en la actualidad pero también (y a veces sobre todo) por su propia historia, por su relación con la del lugar o por su impacto en el viajero. Ese encuentro suscita emociones, reflexiones, evocaciones de otros objetos, personas, acciones, lugares, tiempos, etc. Nos referimos aquí a las digresiones surgidas en conexión directa con la circunstancia viática que se narra, pero teniendo en cuenta que en ocasiones la relación es más relajada o incluso inexistente. Por lo tanto, conviene distinguir tres tipos (asociadas, tangenciales y paralelas), según su conexión con la línea narrativa principal.

Refiriéndonos a su temática, la tipología de la digresión es singularmente rica, por lo que citaremos algunas categorías muy generales observadas con cierta regularidad en los textos analizados: historia, economía, política, antropología, religión, ciencia y técnica, comunicaciones, educación y cultura, lingüística, literatura, bellas artes, biografia, demografia, paisaje, flora y fauna, entre otras. Una variante habitual es la de las historias de segundo grado: narraciones de índole ficcional o factual, vinculadas o no con la diégesis principal, tales como historias oídas a otros personajes, referidas al viaje objeto del relato o a otros, extraídas del pasado del lugar, imaginadas por el mismo viajero, recuerdos de su infancia, etc. Final de novela en Patagonia de Mempo Giardinelli destaca en este punto por la novela insertada, por relatos de hechos previos al periplo y por los sueños del viajero distribuidos a lo largo del texto.

La extensión va desde el comentario en pocas líneas hasta varios capítulos con pretensión de ensayo histórico, social o literario: según subraya el viajero de El Congo estrena libertad de José Luis Castillo-Puche, 
la digresión reflexiva es parte del texto viático. Véanse también obras como Madrid-Moscú de Ramón J. Sender, El viaje de Sergio Pitol o La última vuelta al mundo en 80 días de Luis Pancorbo.

En cuanto al soporte de representación, notemos que el signo gráfico, aunque indispensable, no es el único utilizado: la ilustración, apuntada antes en su función descriptiva, es otra modalidad a tener en cuenta por sus múltiples variantes: fotografias (del viajero, de lugareños, de edificios, de espacios naturales, de transportes, de actividades individuales o colectivas, etc.), caricaturas, dibujos, planos o mapas pueden funcionar como elementos narrativos, descriptivos o digresivos, según su vinculación con la línea argumental.

Así pues, en el discurso viático la digresión no es algo marginal, más bien negativo y fácilmente prescindible: a medida que se avanza en el viaje, aumenta el contacto con la alteridad, lo cual supone disponibilidad para desviarse a derecha o izquierda e impregnarse de lo nuevo, de lo distinto y destacarlo textualmente. Es decir, el principio de progresión se entrevera con el de relación y un buen libro de viaje ha de contener ese doble movimiento. Por consiguiente, lejos de carecer de intriga, el relato viático la tiene por partida doble: respecto al final del viaje y a sus desvíos.

\section{A modo de ejemplo: la literatura de viaje española del siglo XIX}

Para ilustrar la amplitud de este campo de estudio, hemos elegido una etapa clave de la literatura de viaje contemporánea limitándonos a la España del siglo XIX y tomando como base los relatos que tematizan un desplazamiento al exterior del estado. Dejando de lado los de asunto americano (de novedad relativa: se inician con el descubrimiento, si admitimos el diario de Colón), consideramos los referidos a tres grandes destinos: el oriental, el europeo y el norteafricano, en el que nos centraremos para no alargarnos. Así pues, operamos una cuádruple restricción: respecto al tiempo, al lugar de creación, al criterio de selección y, dentro de este, a un único espacio, el norteafricano (lo cual da idea, por contraste, de la extensión potencial del corpus de estudio). Además nos limitaremos a destacar brevemente una serie reducida de autores y de obras dignos de mención. 
En relación con el relato de tema oriental, la presencia de España como potencia colonial o sus relaciones políticas y comerciales con los territorios situados camino de Filipinas, además de las posibles razones del propio viajero (afán exploratorio, curiosidad científica, motivación espiritual, etc.) fueron factores propicios para la aparición de una amplia nómina de escritores viajeros al cercano, al medio y al extremo Oriente. Merecen recordarse, entre otros, los nombres de Domingo Ortiz de Zárate (Viaje por el Istmo de Suez, 1848), Adolfo Rivadeneyra (Viaje de Ceilán a Damasco y Viaje al interior de Persia, 1871 y 1880-1881), Enrique Mhartín Guix (De España a sus Indias. Memorias de un viaje de tres mil leguas, 1885), Enrique Gaspar (Viaje a China, 1887) y José Fernández Giner (Filipinas: Notas de viaje y estancia, 1889). Aunque este destino está aún muy poco estudiado, el lector ya dispone de una lograda introducción en el ensayo de Torres-Pou sobre el tema ${ }^{8}$.

En cuanto al relato de viaje europeo, aunque tal vez menos exaltante que los otros, pues su autor transitaba por un espacio más familiar y accesible (en comunicaciones, documentación, infraestructura hotelera, etc.), generó un notable flujo de viajeros y de textos basados en dos tipos de intereses, por un lado, el afán comparatista: verificar lo leído u oído respecto a tales lugares y hacerse una idea de la distancia socioeconómica existente entre ellos y España. Así lo leemos en Modesto Lafuente (Viajes de Fray Gerundio por Francia, Bélgica, Holanda y orillas del Rhin, 1842), Ángel Fernández de los Ríos (Itinerario descriptivo, pintoresco y monumental de Madrid a París, 1845) y Mesonero Romanos (Recuerdos de viaje, 1862) 9 . Por otro lado, tenemos el relato de viaje de interés artístico, con Italia como referencia esencial para la historia cultural y estética de Europa. Léanse, por ejemplo, Del Ebro al Tíber

\footnotetext{
${ }^{8}$ Francisco Torres-Pou, Orientalismos: Oriente y Occidente en la literatura y las artes de España e Hispanoamérica, Barcelona, Promociones y Publicaciones Universitarias, 2010.

9 Ver nuestro ensayo «Viajeros españoles por Europa en los años cuarenta del siglo XIX: tres formas de entender el relato de viaje», Revista de Literatura, LXXXIII, 2011 (enero-junio), pp. 245-268. Una variante muy notable en este apartado es la de los relatos de viaje a las ferias de muestras, iniciados en los años cuarenta y acentuados a partir de mitad de siglo con las visitas a las exposiciones universales, esencialmente de Londres y de París, que dieron lugar a crónicas y relatos de autores como Wenceslao Ayguals de Izco, José Castro y Serrano, Alfredo Escobar, Emilia Pardo Bazán, etc. Léase, de Luis F. Díaz Larios, "Viajeros españoles a los escaparates del progreso y de la técnica», Boletín Hispánico Helvético, 20, 2012, pp. 135-158.
} 
(1863) de Amós de Escalante, los artículos de Galdós en La Prensa de Buenos Aires (1885-1889) o En el país del arte (1896) de Vicente Blasco Ibáñez ${ }^{10}$.

Refiriéndonos ahora a los relatos de asunto africano, la lista no se para en los firmados por autores tan conocidos como Domingo Badía («Alí Bey»), Pedro Antonio de Alarcón, Ros de Olano, José María de Murga («El Moro Vizcaíno»), Núñez de Arce o Estébanez Calderón. El volumen de producción es tan amplio y variado que se pueden distinguir al menos tres grupos diferentes. Llamaremos al primero 'relato de militar': se trata de textos de relativo decoro literario, debidos a oficiales del ejército español con la misión de conocer las riquezas del territorio marroquí, sus defensas, costumbres, mentalidad y la organización social de sus habitantes, todo con vistas a una posible ocupación del norte africano. Claro que a esta motivación se añade otra más personal, aunque en principio compatible con la anterior: realizar una experiencia única, descubrir, probar y probarse, conocer comparando lo nuevo con lo familiar. Un perfecto ejemplo de este primer grupo es Viajes por Marruecos (1869-1871) de Joaquín Gatell y Folch, militar y jurista quien, ocultando su identidad, llegó a ser jefe de artillería del sultán de Marruecos.

La segunda variante, el 'relato diplomático', acoge obras de autores que se desplazan a África sirviendo a la administración política española, permanecen allí un breve tiempo y redactan un relato de su estancia ya sea como informe o como impresiones y recuerdos de viaje. Son textos quizás de mayor calidad formal que los anteriores pero sin la inmersión en la sociedad del otro que constituye el gran atractivo de aquellos. Una embajada a Marruecos en 1882: apuntes de viaje de Wenceslao Ramírez de Villa-Urrutia ilustra bien los rasgos de este grupo (el autor había acompañado al embajador de España José Diosdado Castillo en su visita a Marruecos).

\footnotetext{
${ }^{10}$ A veces la motivación artística viene vinculada a la religiosa (sobre todo en los viajes a Italia) o a la económico-social (en las visitas a las exposiciones universales) e incluso pueden reunirse las tres en un mismo texto, de tal manera que resulta dificil extraer una prioridad temática. Un excelente ejemplo del triunfo del motivo artístico sobre el económico-político es el del relato de viaje a Alemania de Enrique Gil y Carrasco (1844), reeditado en 2015 por Paradiso-Gutenberg, Coruña, con el título de Último viaje: diario Madrid-París-Berlín. Sobre este autor ha aparecido un ensayo nuestro: «El relato europeo de Gil y Carrasco en el marco de la literatura de viaje española» en Valentín Carrera (ed.), Enrique Gil y Carrasco y el Romanticismo, Santiago de Compostela, Andavira, 2016, pp. 315-338.
} 
La tercera variante, el 'relato científico', llama la atención por su correcta expresión literaria y, sobre todo, por su contradicción interna: bajo la cobertura de una pretensión científica, los prejuicios sobre el pueblo norteafricano, su incapacidad de evolución, la pretendida obligación europea de sacarlo del atraso, etc., marcan una posición ideológica que se podría calificar de colonialista de manera explícita o implícita. En pocas palabras: los textos de este grupo comparten, en gran medida y a veces $\sin$ demasiadas precauciones retóricas, los presupuestos que cabría esperar más bien en los autores anteriores. Véase a este respecto, por ejemplo, Recuerdos de un viaje a Marruecos (1859) del naturalista Fernando Amor y Mayor.

Conviene añadir dos apuntes: primero, el relato africanista tiene un momento de especial relieve a mitad del siglo XIX con motivo de la mal llamada 'Guerra de África' (limitada a cuatro meses y al norte de Marruecos), puesto que el gobierno español impulsa un gran despliegue periodístico para promocionarla ante le opinión nacional, que acabará generando textos notorios de Ros de Olano, Núñez de Arce y, sobre todo, de Alarcón (Diario de un testigo de la guerra de África, 1860); segundo, el asunto marroquí sigue vigente a lo largo del siglo pasado, tanto en la novelística como en la literatura de viaje: recuérdense Aita Tettauen de Galdós, Imán de Sender, Marruecos: de Melilla a Tanger de Luis Antón del Olmet, Notas marruecas de un soldado de Ernesto Giménez Caballero, por citar algunos textos de inicios del siglo Xx. Para el actual, baste recordar la obra de Lorenzo Silva: dos novelas y tres libros de temática viajera, hasta el momento ${ }^{11}$.

Hemos presentado un campo de estudio, un corpus, una metodología, una categorización, un marco espacial, una periodización y un léxico. Queda mucho por hacer en un terreno que implica revisar cánones, divisiones genéricas y jerarquías estéticas y que, en el fondo, cuestiona (interroga y pone en cuestión) la historia misma de la literatura y su

\footnotetext{
${ }^{11}$ Julio Peñate Rivero, «De cómo el sueño deriva en pesadilla: Marruecos en el pasado y en el presente de Lorenzo Silva", en Jean-Henrik Witthaus \& Christian von Tschilschke (eds.), El otro colonialismo, Frankfurt a. M., Vervuert (en imprenta).
} 
relación con el conjunto de las ciencias humanas. Se trata de un formidable desafio, probablemente uno más de los que tienen hoy planteados los estudios literarios, pero también uno de los más atractivos y estimulantes. En definitiva, como nos pregunta Todorov en Les morales de l'histoire, "Qu'est-ce qui n'est pas un voyage?».

Julio PeÑate Rivero

Université de Fribourg - Suisse 